Article

\title{
Quasi-Static and Plate Impact Loading of Cast Magnesium Alloy ML5 Reinforced with Aluminum Nitride Nanoparticles
}

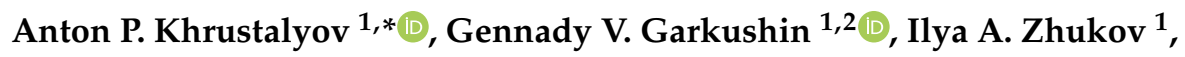 \\ Sergey V. Razorenov ${ }^{1,2}$ and Alexander B. Vorozhtsov ${ }^{1}$ \\ 1 Faculty of Physics and Engineering, National Research Tomsk State University, Tomsk 634050, Russia; \\ garkushin@ficp.ac.ru (G.V.G.); gofra930@gmail.com (I.A.Z.); razsv@ficp.ac.ru (S.V.R.); \\ abv@mail.tomsknet.ru (A.B.V.) \\ 2 Institute of Problems of Chemical Physics, Russian Academy of Sciences, Moscow 142432, Russia \\ * Correspondence: tofik0014@mail.ru; Tel.: +7-9521-555-568
}

Received: 15 May 2019; Accepted: 20 June 2019; Published: 25 June 2019

check for updates

\begin{abstract}
The influence of a small addition of $0.5 \mathrm{wt} . \%$ aluminum nitride nanoparticles with an average size of $80 \mathrm{~nm}$ on the mechanical properties of a cast magnesium alloy under quasi-static tensile (strain rate $10^{-4} \mathrm{~s}^{-1}$ ) and plate impact loading (strain rate $10^{5} \mathrm{~s}^{-1}$ ) was investigated. The composites were obtained by casting with a special mixing vortex device. After casting, some samples were subjected to heat treatment. The introduction of a small number of particles into the liquid metal led to a decrease in matrix grain size and a change in elasto-plastic and strength properties. Compared to quasi-static loading, the pre-heat treatment of tested alloys does not significantly affect the dynamic properties of a reinforced magnesium alloy under shock compression.
\end{abstract}

Keywords: metal-matrix nanocomposite; aluminum nitride nanoparticles; heat treatment; mechanical properties; elastic limit; strength; shock waves

\section{Introduction}

Increased requirements for the mechanical, weight, operational, and other parameters of materials for the aviation, aerospace, military, and other industries in which weight reduction is important require the development of new technological solutions to improve the strength properties of materials. Cast magnesium alloys reinforced with dispersed particles can be used to solve such problems [1,2]. The mechanical properties of these alloys largely depend on grain size [3], the volume fraction [4], and the uniform spatial distribution of particles in a matrix. Casting is the most valid and relatively simple-to-implement method in which nanoparticles are introduced into a liquid metal using a mechanical mixer. A developed special mixing device [5] was used by the authors to introduce $0.75 \mathrm{wt} . \%$ and $1.5 \mathrm{wt} . \%$ AlN nanoparticles (with a size of $100 \mathrm{~nm}$ ) in the cast magnesium alloy ML12 [6]. The device allows for the forming of a homogeneous structure with a reduced matrix grain size from 450 to 230 and $120 \mu \mathrm{m}$, respectively. The composites had a simultaneous increase in strength from 150 to $210 \mathrm{MPa}$ and an elongation from $7 \%$ to $18 \%$. Further improvements in structural parameters, including mechanical properties, can be ob55tained by heat treatments [7,8]. It was shown in [7] that the aging effect on the hardness of composites El21-AlN is significantly less compared with such an effect on the hardness of the initial alloy El21. AlN nanoparticles also allow for the increasing of the heat and electrical conductivity of magnesium alloys [9]. The effect of heat treatment $\mathrm{T} 6 \mathrm{on}$ the improvement of mechanical properties of composites AZ91D/SiC is shown in [8].

The relative contributions of the material structure to deformation resistance can be elucidated experimentally by varying its structure and changing its strain rate [10-12]. Only the parts of structural 
factors that have a strengthening effect at low strain rates can be effective in a high strain rate. Under intense dynamic loading, the high density of microdefects can reduce the dependence of yield strength on the strain rate. The difference in velocity profiles can be so large for titanium and aluminum [13] that it can change the sign of the influence of structural factors under the transition from quasi-static to plate impact loading.

At present, experimental data on the effect of small additions of nano-sized aluminum nitride particles on strength properties of cast metal-matrix magnesium composites in different structural states under quasi-static and plate impact loading are practically absent. The aim of this study is to investigate the effect of small additions of aluminum nitride nanoparticles with an average size of $80 \mathrm{~nm}$ and a volume fraction of $0.5 \mathrm{wt} . \%$ - obtained by casting with a special mixing vortex device-on the mechanical properties. In addition, comparative experiments to determine the elastic-plastic and strength properties of the samples after casting and samples with pre-heat treatment under quasi-static and plate impact loading were carried out.

\section{Materials and Methods}

Samples of the commercial cast magnesium alloy ML5 (AZ91) and the metal-matrix composite ML5/AlN reinforced with ceramic nanosized particles of aluminum nitride (AlN) were obtained. The particles introduced into the melt had an irregular shape with a large number of side planes [6]. The average particle size was $80 \mathrm{~nm}$.

The specimens of the metal-matrix nanocomposite were produced by a casting method under protective flux VI-2 ( $\mathrm{MgCl} 38-46$ wt. $\%, \mathrm{BaCl}_{2} 5-8 \%$ wt.\%, $\mathrm{CaF}_{2} 3-5$ wt. $\%, \mathrm{CalCl}_{2}+\mathrm{NaCl} 10$ wt.\%, and $\mathrm{KCl} 32-40 \mathrm{wt} . \%)$. The magnesium melt ML5 was pre-prepared in an amount of $10 \mathrm{~kg}$ and heated to a temperature of $710^{\circ} \mathrm{C}$. It was then placed in the special pot. After that, the melt was mixed, and, after $15 \mathrm{~s}$, the aluminum nitride of nanoparticles in the amount of $0.5 \mathrm{wt} . \%$ was introduced with simultaneous stirring for $1 \mathrm{~min}$ at a mixer rotation velocity of $500 \mathrm{rpm}$. The initial alloy ML5 was produced with similar parameters (it was mixed and then subjected to vibration treatment to complete crystallization without the introduction of nanoparticles). An original mixing device [5] was used for the mixing of the melt made of the commercial titanium (Figure 1). The mixing device allows for the creation of the turbulent melt flow and the introduction of the powder materials affecting the structure and mechanical properties of metals and alloys. Small vortices, although energetically weaker, can provide uniform mixing, creating regions of uniformity of several tens of microns. According to the experimental results, the use of a special mechanical mixing device allows for the injection of course particles and leads to a significant improvement in the microstructure and mechanical properties of the alloy [5]. During mechanical mixing, the melt was blown with argon. The finished melt was poured into a mold with a size of $700 \times 250 \mathrm{~mm}^{2}$ (Figure 1b). The mold was affected by vibration treatment during crystallization. The measured density of $\rho_{0}$ samples of the initial alloy ML5, and the metal-matrix composite ML5/AlN was $1.8 \pm 0.02 \mathrm{~g} / \mathrm{cm}^{3}$. 

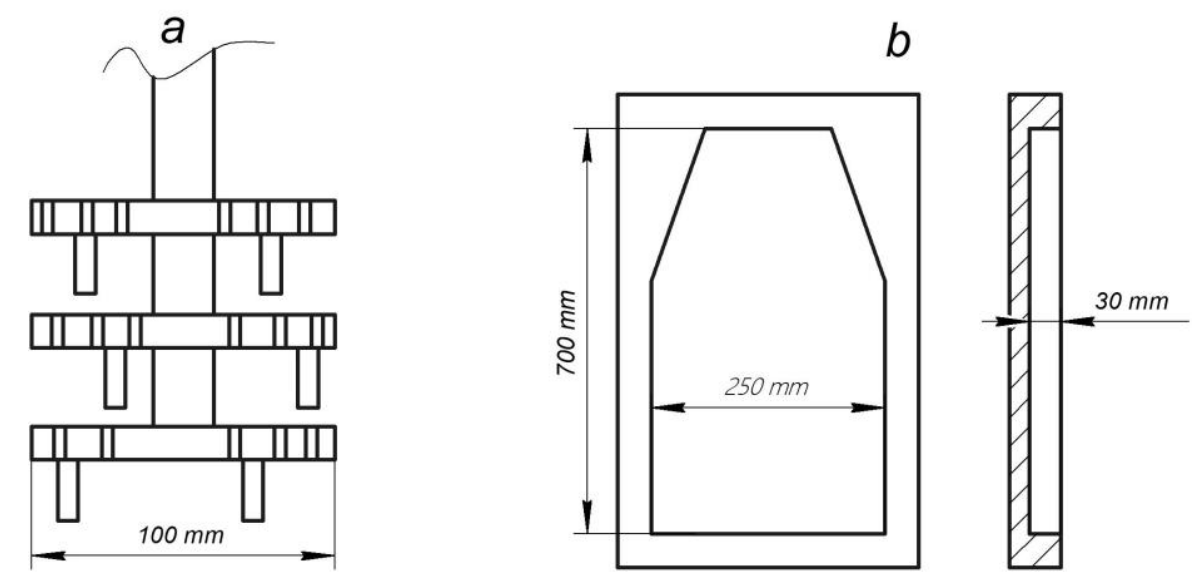

Figure 1. Scheme of the original mixing device for metal melts at high temperature [5] (a); schematics of the mold (b).

The obtained samples of the alloy ML5 and the composite ML5/AIN were subjected to heat treatment T2 (annealing) and T61 (hardening and aging) in air. The annealing was conducted at a temperature of $280^{\circ} \mathrm{C}$ for $4 \mathrm{~h}$, and heating and cooling were carried out in the muffle furnace. Before hardening, the specimens were heated at a temperature of $370^{\circ} \mathrm{C}$ for $2 \mathrm{~h}$, followed by cooling in water with a temperature of $60{ }^{\circ} \mathrm{C}$. After hardening, the samples were subjected to aging at a temperature of $170^{\circ} \mathrm{C}$ for $4 \mathrm{~h}$, followed by cooling in the furnace.

In this work, the microstructure of the samples was investigated using the optical microscope Olympus GX71 (Olympus Scientific Solutions Americas, Waltham, MA, USA). The study of strength properties for materials with quasi-static axial tension was carried out on the electromechanical universal testing machine INSTRON 3369 (INSTRON 8801, Instron European Headquarters, High Wycombe, UK) with a strain rate of $2 \times 10^{-4} \mathrm{~s}^{-1}$. The testing samples were cut from the initial alloy ML5 and the composite ML5/AlN, and the samples obtained after the heat treatment were in the form of flat double-sided blades on a spark erosion machine. The dimensions of the working part of the samples on tension were $40 \times 8 \times 1 \mathrm{~mm}^{3}$. The guaranteed frame rigidity of the testing machine corresponds to a load of $250 \mathrm{kN}$, and the measurement accuracy is $0.5 \%$ of a specified load.

The samples for the shock-wave experiments were cut from the castings of magnesium alloy with different structures by the electric-spark method in the form of tablets with a diameter of $15 \mathrm{~mm}$ and $30 \mathrm{~mm}$, with a thickness of $2 \pm 0.05 \mathrm{~mm}$ and $5 \pm 0.05 \mathrm{~mm}$, respectively. The strain rates in the shock wave less than $10^{6} \mathrm{~s}^{-1}$ were realized by loading the samples with planar shock waves. The waves were generated in the samples during collision with aluminum plates (impactors) with a diameter of $70 \mathrm{~mm}$ and a thickness of $0.38 \pm 0.02 \mathrm{~mm}, 0.73 \pm 0.02 \mathrm{~mm}$, and $2 \pm 0.02 \mathrm{~mm}$, and they were accelerated to a velocity of $630 \pm 30 \mathrm{~m} / \mathrm{s}$ using special flat-wave shock-wave generators (explosive lens) [14]. Figure 2 demonstrates the experimental assembly for the shock-wave loading of the tested specimens. The shock wave generators provide the necessary loading conditions and the high degree of homogeneity for the sample deformation, which was achieved by the impact of parallel-sided plates. Under such loading, the shock wave is excited in the sample, after which a constant state is maintained during the time of wave circulation in the impactor.

The velocity of the free back surface of the samples $u_{f_{s}}(t)$ was continuously recorded during all shock-wave loading experiments using a laser Doppler velocimeter VISAR (velocity interferometric system for any reflection) [15]. The free surface velocity profiles $u_{f s}(t)$ were recorded with a resolution of $1 \mathrm{~ns}$ in time and $3 \mathrm{~m} / \mathrm{s}$ in measured velocity value. 


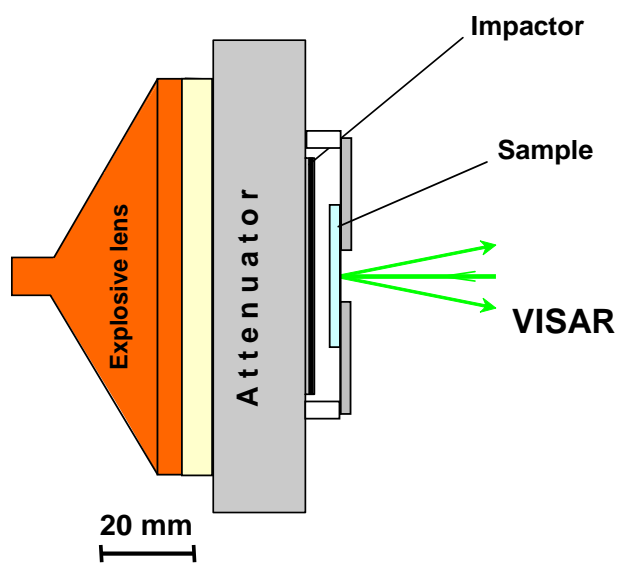

Figure 2. Scheme of the shock-wave loading of samples using the explosive generator.

\section{Results and Discussion}

\subsection{Quasi-Static Loading Hardness}

It was shown that the alloy structure in the as-cast condition and without the heat treatment is represented by coarse grains of the solid solution. The grain size varied from 400 to $800 \mu \mathrm{m}$, and the average calculated size was $610 \mu \mathrm{m}$. The introduction of $0.5 \mathrm{wt} . \%$ AlN nanoparticles led to the formation of a more homogeneous microstructure of the alloy-the grain size varied from 350 to $450 \mu \mathrm{m}$, and the average grain size was about $420 \mu \mathrm{m}$ (Figure 3).
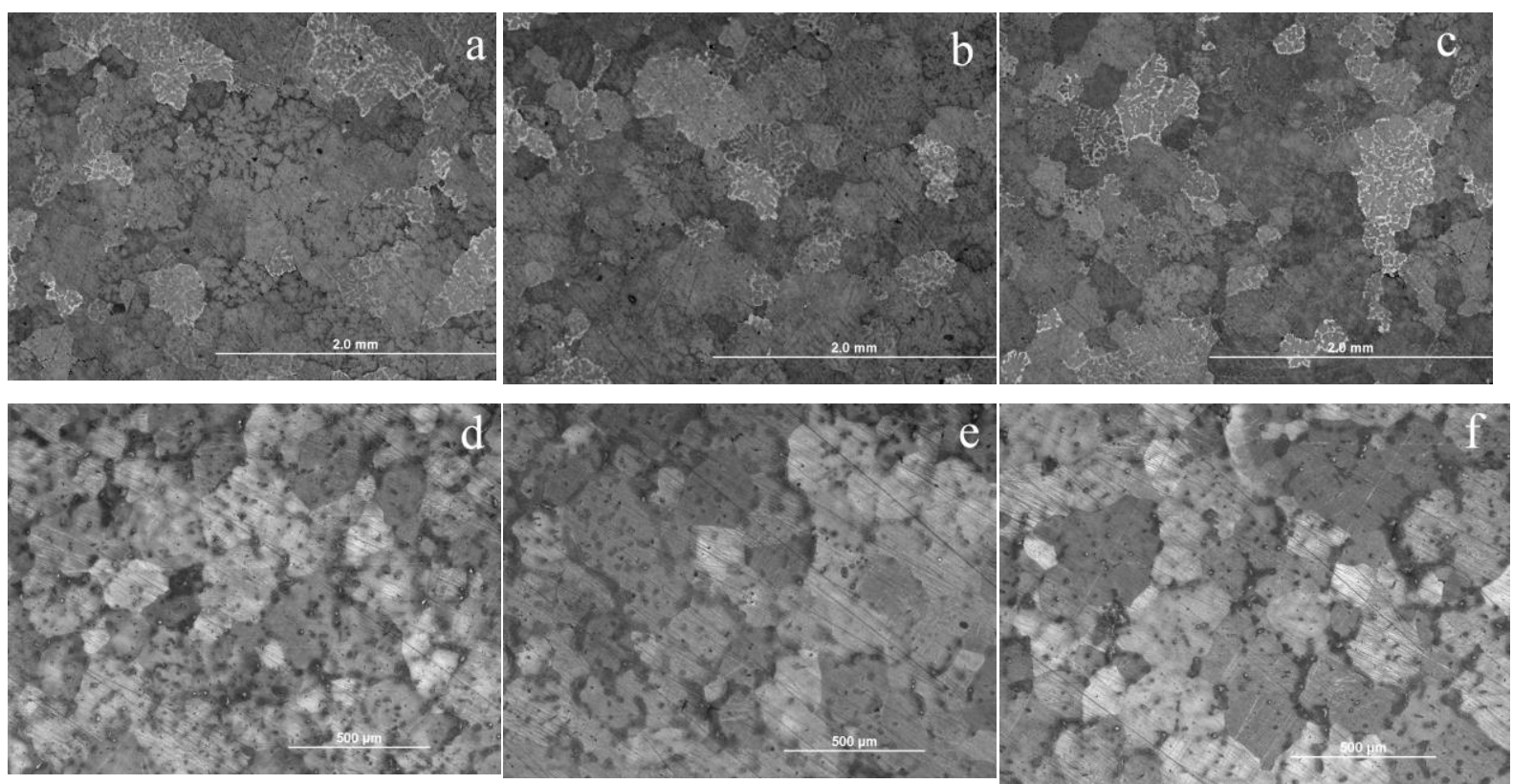

Figure 3. Optical images of microstructures: ML5 reference (a), ML5/AIN (b), ML5 T2 (c), ML5/AIN T2 (d), ML5 T61 (e), and ML5/AlN T61 (f).

As noted in [16], the effect of the grain refinement results from the heterogeneous nucleation of the primary phase on AlN particles and the restriction of crystal growth caused by the presence of AIN particles (Figure 4). 


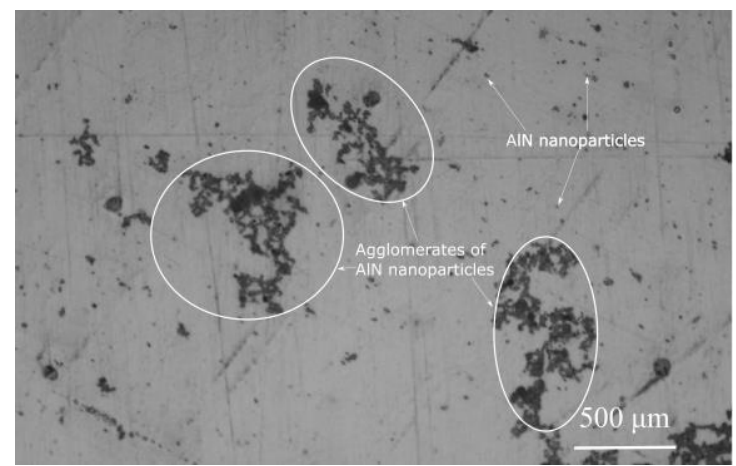

Figure 4. Optical micrograph of the surface of the composite ML5/AlN.

A large number of aluminum nitride nanoparticles agglomerated during their introduction into the melt, and these were found when analyzing the composite microstructure without the etching of the surface. Probably, the effect of grain refinement from the introduction of nanoparticles is not fully implemented, but, at the same time, it is possible to expect an increase in the mechanical properties of the alloy due to the introduction of individual particles into the grain shape. The annealing of the alloy ML5 led to the elimination of segregation in cast specimens. In other words, there was a dissolution of excess phases disengaged during casting, and the chemical composition was levelled by the grain bulk. As a result of heating under hardening, the net of grain boundary precipitation diffused and formed a homogeneous solid solution. The aging led to the precipitation of strengthening phases from the solution, which reduced the plasticity.

The stress-strain curves of all types of tested samples are shown in Figure 5.

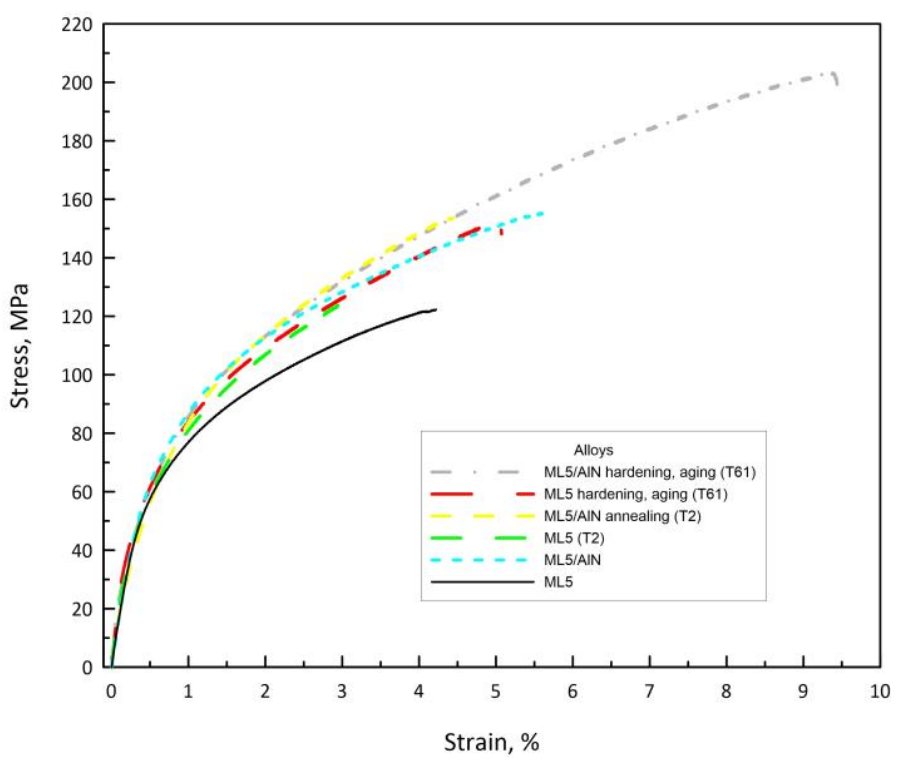

Figure 5. Diagram of axial tension in the alloy for a different structural state.

The stress-strain curves of all types of tested samples are presented in Figure 5. The diagram (Figure 5) shows that the initial cast alloy ML5 had poor parameters. The introduction of aluminum nitride nanoparticles into the alloy ML5 led to an increase in the offset yield strength $\left(\sigma_{0.2}\right)$ from 55 to $70 \mathrm{MPa}$, the tensile strength from 122 to $155 \mathrm{MPa}$, and the plasticity from $4 \%$ to $5.5 \%$. In [17], the introduction of aluminum nitride nanoparticles contributed to an improvement in the ductility of magnesium alloy. The improvement of the mechanical properties of the alloy is related to the grain structure refinement of magnesium alloy. In addition, the presence of macroscopic cracking at twin boundaries is assumed to be the reason for improved ductility [17]. 
Minor variation in the yield strength of $2 \%$, the tensile strength of $4 \%$, and the plasticity from $4 \%$ to $3 \%$ were observed for the samples of the initial alloy ML5 after annealing. A significant decrease in the yield strength from 70 to $59 \mathrm{MPa}$ and the plasticity from $5.5 \%$ to $4.5 \%$ was demonstrated by the samples of the annealed composite ML5/AIN, but the tensile strength did not change and equaled $155 \pm 14 \mathrm{MPa}$. Hardening along with aging for the alloy ML5 and the composite ML5/AIN led to highly improved mechanical properties. Maximum strength values of 203 MPa were observed for the composite ML5/AlN, while the yield strength remained at $49 \mathrm{MPa}$.

Rockwell hardness values were determined for the tested samples using a unit TN-300, a steel indenter with a diameter of $1.6 \mathrm{~mm}$, a force of $60 \mathrm{kgf}$, and a holding time of $3 \mathrm{~s}$. The results of the hardness measurement show its decrease for the samples after heating T61 for both the cast alloy and the composite, while the strength properties increased. The generalized data obtained in the study process of the structure and mechanical properties of the obtained samples are presented in Table 1.

Table 1. The measurement results of the mechanical properties and hardness.

\begin{tabular}{cccccc}
\hline Alloy & Grain Size, $\mu \mathrm{m}$ & HRF & $\boldsymbol{\sigma}_{\mathbf{0 . 2}}, \mathbf{M P a}$ & $\boldsymbol{\sigma}_{\mathbf{B}}, \mathbf{M P a}$ & Plasticity, $\%$ \\
\hline ML5 reference & $610 \pm 22$ (Figure 3a) & $62.2 \pm 3$ & $55 \pm 10$ & $122 \pm 18$ & $4 \pm 0.5$ \\
\hline ML5/AlN & $420 \pm 14$ (Figure 3b) & $62.6 \pm 3$ & $70 \pm 12$ & $155 \pm 14$ & $5.5 \pm 0.3$ \\
\hline $\begin{array}{c}\text { ML5 } \\
\text { (T2) }\end{array}$ & $624 \pm 20$ (Figure 3c) & $63.1 \pm 3$ & $59 \pm 15$ & $126 \pm 22$ & $3 \pm 0.4$ \\
\hline $\begin{array}{c}\text { ML5/AlN } \\
\text { (T2) }\end{array}$ & $381 \pm 18$ (Figure 3d) & $64.5 \pm 3$ & $46 \pm 11$ & $154 \pm 15$ & $4.5 \pm 0.2$ \\
\hline ML5 (T61) & $649 \pm 25$ (Figure 3e) & $54 \pm 3$ & $56 \pm 17$ & $152 \pm 25$ & $5 \pm 0.6$ \\
\hline ML5/AlN (T61) & $415 \pm 14$ (Figure 3f) & $52.7 \pm 3$ & $49 \pm 16$ & $203 \pm 21$ & $9 \pm 0.9$ \\
\hline
\end{tabular}

\section{Results of Shock-Wave Deformation and Fracture}

The measurement results of the free surface velocity profiles $u_{f_{s}}(t)$ for the samples of the alloy ML5 and the metal-matrix composite ML5/AIN after casting are shown in Figure 6. The thickness of the samples was $4.89 \mathrm{~mm}$, and the thickness of impactors was $2 \mathrm{~mm}$ in these experiments.

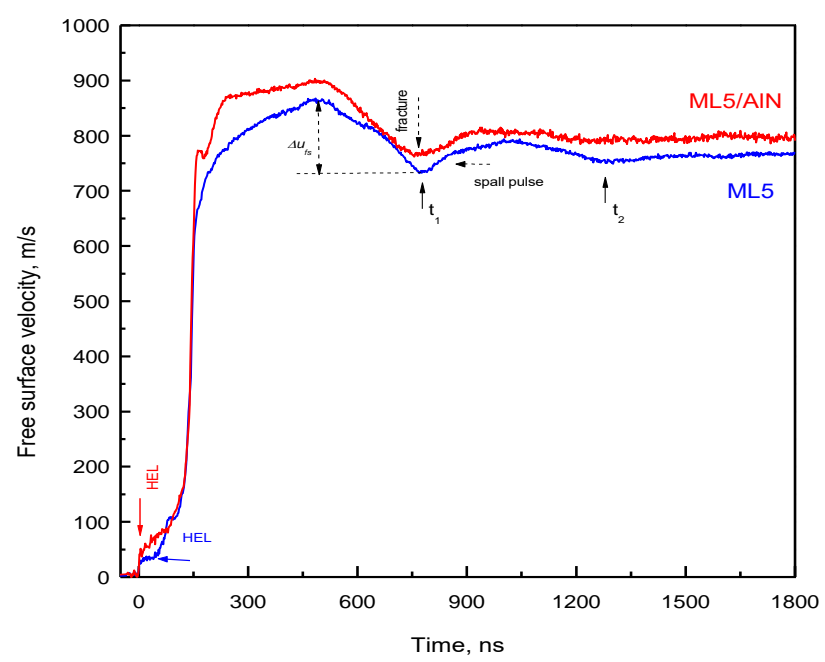

Figure 6. Free surface velocity histories of the cast magnesium alloy ML5 and the metal-matrix composite ML5/AlN after casting [16] without the heat treatment.

The exit to the surface of the elastoplastic compression wave and part of the following rarefaction wave was recorded on the wave profiles. The compressive stress behind the elastic precursor front corresponded to the Hugoniot elastic limit (HEL) $\sigma_{\mathrm{HEL}}=\rho_{0} c_{l} u_{f_{s}} \mathrm{HEL} / 2$ of the material under uniaxial 
compression, where $\rho_{0}$ is the material density, $c_{l}$ is the longitudinal speed velocity (5778 \pm 10$)$, and $u_{f s} \mathrm{HEL}$ is the surface velocity at the elastic precursor front (HEL velocity on the wave profile). The corresponding values of yield strengths under conditions of the uniaxial tensile stress $\sigma_{\mathrm{T}}$ are related to $\sigma_{\mathrm{HEL}}$ as follows: $\sigma_{\mathrm{T}}=3 / 2 \sigma_{\mathrm{HEL}}\left(1-c_{b}{ }^{2} / c_{l}^{2}\right)$, where $c_{b}$ is the bulk sound velocity $(4500 \mathrm{~m} / \mathrm{s})$. After the compression pulse was reflected from the free surface, tensile stresses were generated inside the sample upon reaching the critical values of which its fracture (in other words, spall) was triggered. In this case, the relaxation of tensile stresses occurred, and a compression wave (spall pulse) was formed, the exit of which to the sample surface caused the second rise in its velocity. A high-rate fracture during the spall is the kinetic process of nucleation. The growth and the fusion of numerous discontinuities, as well as the realizable values of fracture resistance, are the competition results for the growth of tensile stresses in the process of wave interactions and its relaxation as a result of the appearance and the growth of discontinuities in the material.

The decrement of the surface velocity $\Delta u_{f s}$ during its fall from the maximum to the value before the front of the spall pulse was proportional to the magnitude of breaking stress (spall strength of the material under these loading conditions). A value of the spall strength in the linear (acoustic) approximation [16] is calculated as:

$$
\sigma_{\text {spall }}=\frac{1}{2} \rho_{0} c_{b}\left(\Delta u_{f s}+\delta\right),
$$

where $\delta$ is the distortion correction of the velocity profile due to the difference in the velocity of the front of the spall pulse and the velocity of the plastic part of falling depression wave before the pulse. Such distortions [18] occur when a compression wave is generated in a stretched material due to the stress relaxation under fracture. The front of the wave is an elastic wave, and it raises the plastic part of the incident wave of unloading which moves with the bulk sound velocity $\left(c_{b}\right)$. The thickness of the spall plate $h_{\text {spall }}$ is determined from the surface velocity profile $u_{f s}(t)$ on the period of the velocity oscillations. The wave reflects inside the spall plate many times, and its front moves with the longitudinal sound velocity; therefore, when using the oscillation period of the velocity after the spall $\Delta t=\left(t_{2}-t_{1}\right)$, the value of $h_{\text {spall }}$ is defined as $h_{\text {spall }}=c_{l} \Delta t / 2$.

Figure 6 directly shows that the alloy ML5 in the experiments had a lower Hugoniot elastic limit than the composite ML5/AlN, with values of $174 \mathrm{MPa}$ and $268 \mathrm{MPa}$, respectively. The increase in the Hugoniot elastic limit was caused by the decrease in the grain size and the presence of small additions of aluminum nitride nanoparticles. It should be noted that the specimens had the same hardness values. Strain hardening immediately after the exit of elastic compression wave (elastic precursor) was observed on the wave profile of the samples of the composite ML5/AIN. AIN nanoparticles make a significant contribution to the development of the strain hardening because they prevent the movement of dislocations during deformation. The second increase in the velocity was observed after the exit of elastic precursor (before the exit of plastic shock wave) on the wave profile of the alloy ML5. Probably, the distortion of the elastic wave occurred as a result of its propagation through the sample, since the structure of the alloy ML5, after casting, was highly heterogeneous; the grain sizes were rather large, from 400 to $800 \mu \mathrm{m}$, they were not oriented, and they practically worked as separate crystals. A significant change in the Hugoniot elastic limit depending on the crystal orientation was shown in the study of anisotropy in the shock-wave experiments with magnesium single-crystals [18].

As shown in the wave profile of the sample of the composite ML5/AIN (Figure 6), the spall fracture of the material occurred, but further oscillations in the spall plate quickly decayed due to the strong dispersion of the spall pulse on the fracture surface in the spall zone. Such a developed surface may occur as a result of the viscous-plastic fracture of samples. These data obtained completely corresponded with data obtained on the uniaxial tensile testing, where it was shown that the addition of AlN particles leads to an increase in plasticity.

The comparison of wave profiles for the samples of the cast magnesium alloy ML5 and the metal-matrix composite ML5/AlN before and after the heat treatments are presented in Figures 7 and 8 . 


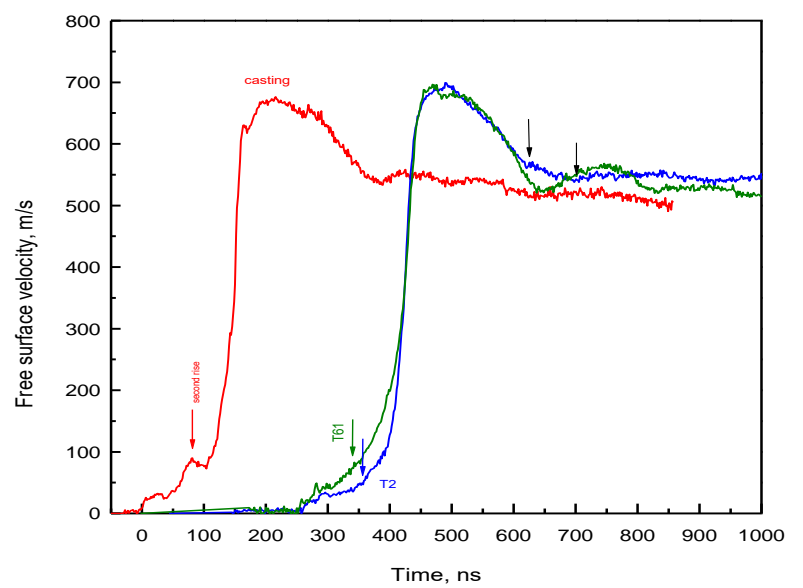

Figure 7. Free surface velocity profiles for the samples of the cast magnesium alloy ML5 before and after heat treatment (annealing; hardening and aging).

The thickness of the samples was $5 \mathrm{~mm}$, and the thickness of impactors was $0.73 \mathrm{~mm}$ in these experiments. With the selected ratio of the thicknesses of the impactor and the sample, loading conditions near the free back surface of the sample corresponded to the onset of shock wave attenuation due to the effect of rarefaction wave catching it. An intermediate rise in the velocity between the elastic and plastic waves was observed on the wave profile of the alloy ML5 after casting (Figure 7). A similar behavior was observed in the experiments shown in Figure 6, which, in both cases, was due to the heterogeneity of the structure of the alloy ML5. An increase in the Hugoniot elastic limit compared with the samples after casting from 158 to $168 \mathrm{MPa}$ was shown on the free surface velocity profile of the sample of the alloy ML5 after annealing (Figure 7). The fracture of the sample became more viscous, and the fluctuations of the surface velocity for the spall plate disappeared almost immediately. The spall strength of the alloy ML5 decreased relative to the sample after casting from 635 to $610 \mathrm{MPa}$. The Hugoniot elastic limit increased up to $255 \mathrm{MPa}$ with sufficiently strong strain hardening in the experiments with hardened and aged samples of the alloy ML5. The plasticity reduction led to the formation of a pronounced spall pulse in the spall plate.

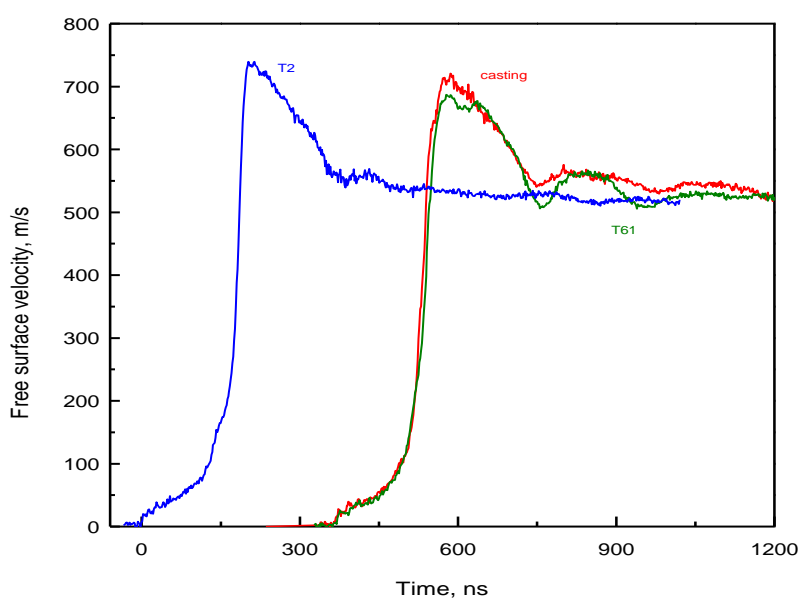

Figure 8. Free-surface velocity profiles for samples of ML5/AIN metal-matrix composite before and after heat treatment (annealing; hardening and aging).

The free surface velocity profiles of the metal-matrix composite ML5/AIN in different structural states are presented in Figure 8. It can be seen from the free surface velocity profiles of the tested samples that the change in the internal structure of the metal-matrix composite ML5/AlN using the heat treatment practically did not effect the Hugoniot elastic limit, and the slight increase in the spall 
strength from 820 to $850 \mathrm{MPa}$ was observed only for the samples subjected to hardening and aging, in comparison with samples after casting and homogenization annealing.

The free surface velocity profiles for the samples of the magnesium alloy ML5 in comparison with the metal-matrix composite ML5/AIN after the heat treatment, namely hardening and aging, are presented in Figure 9. It was shown that the heat-treated cast alloy ML5 had elastic-plastic and strength properties which were practically equal to the composite ML5/AIN. There was sufficiently strong strain hardening for both the alloy ML5 and the composite ML5/AlN. A viscosity of the material or the stress relaxation time was determined by the rise time of parameters in the plastic shock wave.

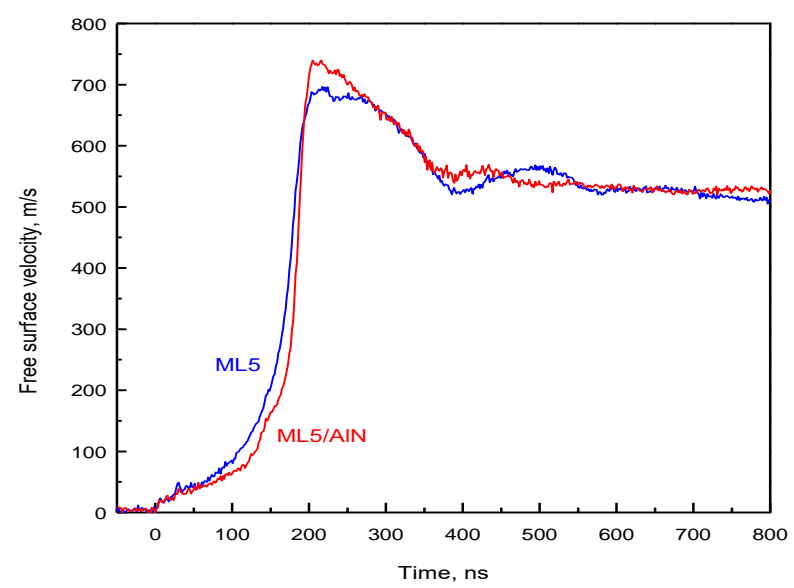

Figure 9. Free surface velocity profiles for the samples of the magnesium alloy ML5 and the metal-matrix composite ML5/AIN.

The summarized values of the Hugoniot elastic limit $\left(\sigma_{\mathrm{HEL}}\right)$ and the spall strength $\left(\sigma_{\text {spall }}\right)$, depending on the structure state of the samples under shock-wave loading, are depicted in Figure 10. It can be seen that the highest value of the Hugoniot elastic limit was received with the samples after hardening and aging. The heat treatment of the composites ML5/AIN had little effect on the parameters of the elastoplastic transition. The strength properties of the samples varied depending on their structural state. The hardening and aging of the alloy samples ML5 allowed for a significant increase of the spall strength and practically achieved the strength of the metal-matrix composite after casting and annealing.

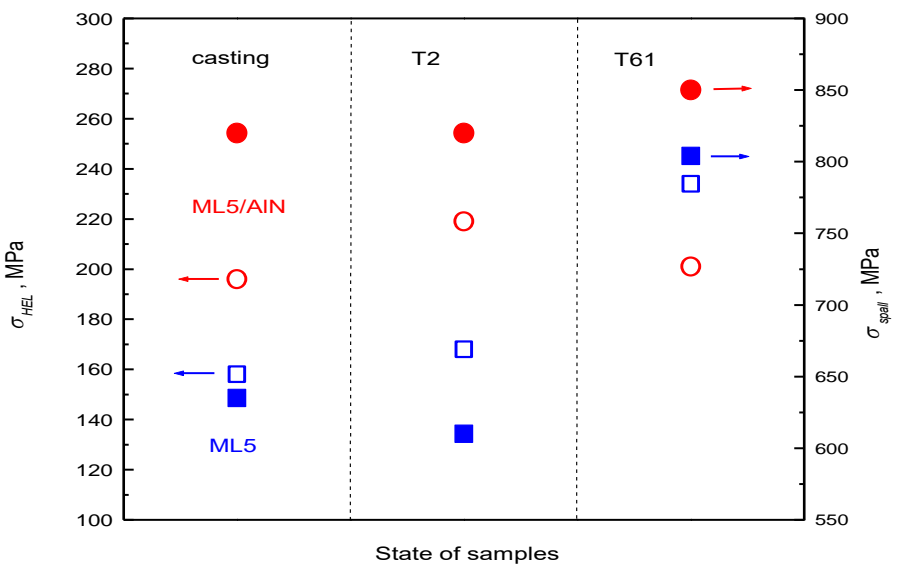

Figure 10. Comparison of Hugoniot elastic limit values (empty symbols) and the spall strength (filled symbols) for the alloy ML5 and the metal-matrix composite ML5/AIN, depending on the initial structural state. 
The dependence of the magnitude of the critical fracture stresses during spallation on strain rates before the spalling in the tested samples, in comparison with data (from scientific literature) for magnesium single crystals, the primary magnesium Mg95, and the alloys of Ma1 and Ma2-1, are presented in Figure 11. Here, the strain rate refers to the expansion rate of the substance in the rarefaction wave, which is defined as $V / V_{0}=u_{f s r} / 2 c_{b}$, where $u_{f s r}$ is the measured rate of decrease of the free sample surface in the discharge part of the shock compression pulse.

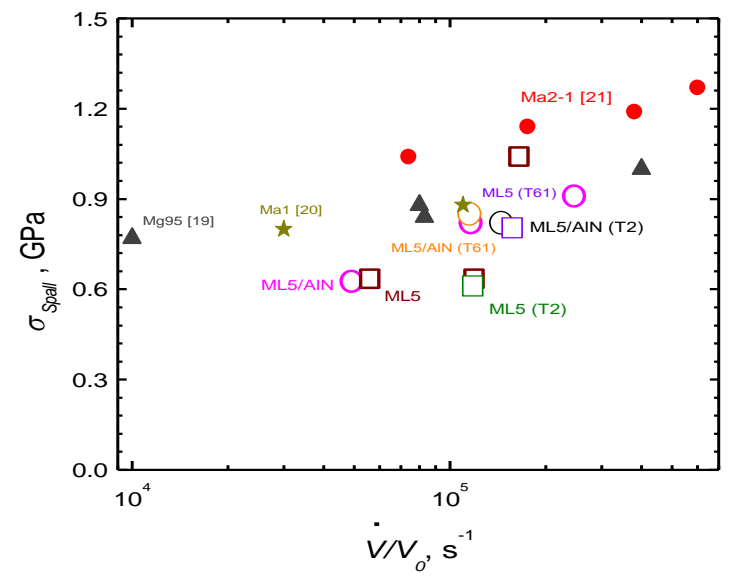

Figure 11. Results of the measurements of the spall strength for the alloy ML5 and the metal-matrix composite ML5/AIN depending on the strain rate in the rarefaction wave. Data from the literature are shown as following symbols: Triangles are the primary magnesium Mg95 [19]; asterisks are the magnesium plate Ma1 [20]; and filled circles are the rod Ma2-1 [21].

The measurement results of the spall strength indicate its increase with the growth of the stretch rate, and these results are generally consistent with the research in [19-21]. As shown in Figure 11, the values of the spall strength of the metal-matrix composite ML5/AlN were almost equal to the spall strength of the deformable magnesium alloy Ma1 [20] at a strain rate of $1.15 \times 10^{5} \mathrm{~s}^{-1}$.

The measurement results of the Hugoniot elastic limit and the spall strength of the samples of magnesium alloy ML5 and the metal-matrix composite ML5/AIN in different structural states obtained from the processing of the measured free surface velocity profiles are presented in Table 2. The corresponding values of the thickness of the spall plate $h_{\text {spall }}$ and the dynamic yield strength are also given there. The maximum shock compression pressure in these experiments varied in a range of 2.99-4.1 GPa, and the strain rate of the samples in unloading before the spall fracture was in a range from $0.5 \times 10^{5} \mathrm{~s}^{-1}$ to $2.5 \times 10^{5} \mathrm{~s}^{-1}$.

Table 2. The measurement results of the Hugoniot elastic limit and the spall strength for the samples of the magnesium alloy ML5 and the metal-matrix composite ML5/AIN in different structural states.

\begin{tabular}{ccccccc}
\hline Sample & State & $\boldsymbol{h}_{\text {sample, }} \mathbf{m m}$ & $h_{\text {hammer }}, \mathbf{m m}$ & $\boldsymbol{\sigma}_{\text {HEL }} / \sigma_{T}, \mathbf{M P a}$ & $\boldsymbol{\sigma}_{\text {spall }}, \mathbf{M P a}$ & $\mathbf{h}_{\text {spall }}, \mathbf{m m}$ \\
\hline ML5 (Figure 6) & casting & 4.895 & 2.009 & $174 / 102$ & 634 & 1.43 \\
\hline ML5/AIN (Figure 6) & casting & 4.890 & 1.995 & $268 / 157$ & 626 & 1.28 \\
\hline ML5 (Figure 7) & casting & 4.894 & 0.732 & $158 / 93$ & 635 & 0.32 \\
\hline ML5/AIN (Figure 8) & casting & 4.898 & 0.725 & $196 / 115$ & 820 & 0.64 \\
\hline ML5 (Figure 7) & annealing & 4.900 & 0.729 & $168 / 99$ & 610 & 0.47 \\
\hline ML5/AIN (Figure 8) & annealing & 4.884 & 0.731 & $219 / 129$ & 820 & 0.557 \\
\hline ML5 (Figure 7) & $\begin{array}{c}\text { Hardening } \\
\text { aging }\end{array}$ & 4.846 & 0.720 & $234 / 139$ & 804 & 0.502 \\
\hline ML5/AIN (Figure 8) & $\begin{array}{c}\text { Hardening } \\
\text { aging }\end{array}$ & 4.860 & 0.720 & $201 / 119$ & 850 & 0.34 \\
\hline
\end{tabular}




\section{Conclusions}

The samples of the metal-matrix composite ML5/AIN were obtained with the purpose of identifying the effect of small additions of ceramic aluminum nitride nanoparticles on the deformation behavior of the magnesium cast alloy ML5 during quasi-static and shock-wave deformation. The mechanical properties of the AIN composite increased in both experiments- under both quasi-static and shock-wave loading. The resistance of the material deformation is primarily related to the grain structure refinement of the magnesium alloy, and it is secondly affected by the presence of nanoparticles in the grain bulk. The stabilization and homogenization of the structure were carried out by using heat treatments—namely annealing and hardening —along with aging for the purpose of the further improvement of the mechanical properties of the alloys. The annealing of the alloy ML5 and the composite ML5/AlN had little effect on their elastic-plastic and strength properties. The highest growth of the Hugoniot elastic limit (255 MPa) compared to the metal-matrix composite ML5/AlN was achieved by the hardening and aging of the samples of the alloy ML5. At the same time, the spall strength slightly increased from 804 to $850 \mathrm{MPa}$. The increase of the strength of the metal-matrix composite ML5/AIN from $155 \mathrm{MPa}$ to $203 \mathrm{MPa}$ was observed under quasi-static deformation and was compared to the samples after casting. The deformation behavior of samples after the heat treatment of the alloy ML5 and the metal-matrix composite ML5/AIN under shock-wave loading became almost the same. The heat treatment of the metal-matrix composite ML5/AIN had little effect on its deformation behavior under the shock compression. The values of the spall strength of the metal-matrix composite ML5/AlN were almost equal to the spall strength values of the deformable magnesium alloy Ma1 at a strain rate of $1.15 \times 10^{5} \mathrm{~s}^{-1}$.

Author Contributions: A.P.K.-idea of the paper, alloys production, materials structure research, analysis of results; G.V.G.-idea of the paper, shock wave loading experiment, analysis of results, summary of results; I.A.Z.- choice of research methods, heat treatment, mechanical testing; S.V.R.—-supervisor, analysis of results; A.B.V.-supervisor, choice of research methods analysis of results.

Funding: This research was funded by Russian Science Foundation, grant number 17-13-01252.

Acknowledgments: The research was supported by grant from the Russian Science Foundation (project No. 17-13-01252). Explosive experiments were conducted in the Moscow regional explosive center for collective use of equipment at the Russian Academy of Sciences.

Conflicts of Interest: The authors declare no conflict of interest. The funders had no role in the design of the study; in the collection, analyses, or interpretation of data; in the writing of the manuscript, or in the decision to publish the results.

\section{References}

1. Ferguson, J.B.; Sheykh-Jaberi, F.; Kim, C.-S.; Rohatgi, P.K.; Cho, K. On the strength and strain to failure in particle-reinforced magnesium metal-matrix nanocomposites (Mg MMNCs). Mater. Sci. Eng. A 2012, 558, 193-204. [CrossRef]

2. Gupta, M.; Wong, W.L.E. Magnesium-based nanocomposites: Lightweight materials of the future. Mater. Charact. 2015, 105, 30-46. [CrossRef]

3. Vaidya, A.R.; Lewandowski, J.J. Effects of $\mathrm{SiCp}$ size and volume fraction on the high cycle fatigue behavior of AZ91D magnesium alloy composites. Mater. Sci. Eng. A 1996, 220, 85-92. [CrossRef]

4. Chen, J.; Bao, C.; Chen, W.; Zhang, L.; Liu, J. Mechanical Properties and Fracture Behavior of Mg-Al/AlN Composites with Different Particle Contents. J. Mater. Sci. Technol. 2017, 33, 668-674. [CrossRef]

5. Vorozhtsov, S.; Minkov, L.; Dammer, V.; Khrustalyov, A.; Zhukov, I.; Promakhov, V.; Vorozhtsov, A.; Khmeleva, M. Ex Situ Introduction and Distribution of Nonmetallic Particles in Aluminum Melt: Modeling and Experiment. JOM 2017, 69, 2653-2657. [CrossRef]

6. Khrustalyov, A.P.; Vorozhtsov, S.A.; Zhukov, I.A.; Promakhov, V.V.; Dammer, V.K.; Vorozhtsov, A.B. Structure and Mechanical Properties of Magnesium-Based Composites Reinforced with Nitride Aluminum Nanoparticles. Russ. Phys. J. 2017, 59, 2183-2185. [CrossRef] 
7. Saboori, A.; Padovano, E.; Pavese, M.; Dieringa, H.; Badini, C. Effect of Solution Treatment on Precipitation Behaviors, Age Hardening Response and Creep Properties of Elektron21 Alloy Reinforced by AlN Nanoparticles. Materials 2017, 10, 1380. [CrossRef] [PubMed]

8. Muley, A.V.; Aravindan, S.; Singh, I.P. Nano and hybrid aluminum based metal matrix composites: An overview. Manuf. Rev. 2015, 2, 1-13. [CrossRef]

9. Saboori, A.; Padovano, E.; Pavese, M.; Badini, C. Novel Magnesium Elektron21-AlN Nanocomposites Produced by Ultrasound-Assisted Casting; Microstructure, Thermal and Electrical Conductivity. Materials 2018, 11, 27. [CrossRef] [PubMed]

10. Huang, J.C.; Lo, Y.-S.; Gray, G.T., III. The response of metal-matrix composites subjected to quasi-static and shock-wave deformation. Mater. Chem. Phys. 1993, 35, 71-85.

11. Yu, X.; Li, T.; Li, L.; Liu, S.; Li, Y. Influence of initial texture on the shock property and spall behavior of magnesium alloy AZ31B. Mater. Sci. Eng. A 2017, 700, 259-268. [CrossRef]

12. Guden, M.; Hall, I.W. Dynamic properties of metal matrix composites: a comparative study. Mater. Sci. Eng. A 1998, 242, 141-152. [CrossRef]

13. Kanel, G.I.; Razorenov, S.V.; Utkin, A.V.; Fortov, V.E. Shock-wave phenomena in condensed matter; Springer Science \& Business Media: New York, NY, USA, 2004.

14. Barker, L.M.; Hollenbach, R.E. Laser interferometer for measuring high velocities of any reflecting surface. J. Appl. Phys. 1972, 43, 4669-4675. [CrossRef]

15. Garkushin, G.V.; Ignatova, O.N.; Kanel, G.I.; Meyer, L.W.; Razorenov, S.V. Submicrosecond Strength of Ultrafine-Grained Materials. Mech. Solids 2010, 45, 624-632. [CrossRef]

16. Khrustalyov, A.P.; Garkushin, G.V.; Zhukov, I.A.; Razorenov, S.V. The Influence of the Structure of a Magnesium-Aluminum Nitride Metal-Matrix Composite on the Resistance to Deformation under Quasi-Static and Dynamic Loading. Technol. Phys. Lett. 2018, 44, 912-915. [CrossRef]

17. Dieringa, H.; Katsarou, L.; Buzolin, R.; Szakács, G.; Horstmann, M.; Wolff, M.; Mendis, C.; Vorozhtsov, S.; StJohn, D. Ultrasound Assisted Casting of an AM60 Based Metal Matrix Nanocomposite, Its Properties, and Recyclability. Metals 2017, 7, 388. [CrossRef]

18. Kanel, G.I.; Garkushin, G.V.; Savinykh, A.S.; Razorenov, S.V.; De Resseguier, T.; Proud, W.G.; Tyutin, M.R. Shock response of magnesium single crystals at normal and elevated temperatures. J. Appl. Phys. 2014, 116, 143504. [CrossRef]

19. Kanel, G.I.; Razorenov, S.V.; Bogatch, A.A.; Utkin, A.V.; Fortov, V.E.; Grady, D.E. Spall fracture properties of aluminum and magnesium at high temperatures. J. Appl. Phys. 1996, 79, 8310-8317. [CrossRef]

20. Kanel, G.I.; Razorenov, S.V.; Fortov, V.E. Spall strength of metals in a wide range of load durations. Sov. Phys. Dokl. 1984, 275, 369-371. (In Russian)

21. Garkushin, G.V.; Kanel, G.I.; Razorenov, S.V. High Strain Rate Deformation and Fracture of the Magnesium Alloy Ma2_1 under Shock Wave Loading. Phys. Solid State 2012, 54, 1079-1085. [CrossRef] 